\title{
Safety of Laparoscopy Assisted Gastrectomy for Gastric Cancer, Including Advanced Cancers
}

\author{
Eun Mee Park, M.D., Hyung Ook Kim, M.D., Ph D., Byung Ho Son, M.D., Ph D., Jun Ho Shin, M.D., Ph D., Sung Ryol Lee, M.D., Ph D. \\ Department of Surgery, Sungkyunkwan University School of Medicine, Seoul, Korea
}

Purpose: Laparoscopy-assisted gastrectomy (LAG) is considered an alternative treatment option for gastric cancer. LAG is safe, however the long-term oncologic efficacy and survival of patients including those with advanced gastric cancer have not been assessed. The aim of this study was to evaluate long-term outcomes and survival of patients with gastric cancer, including advanced cases, who underwent LAG performed by a single surgeon.

Methods: Between January 2006 and December 2010, 161 patients with gastric cancer underwent LAG performed by a single surgeon. Clinicopathological data were collected retrospectively along with data on survival and prognosis. Overall survival (OS) and disease-free survival (DFS) were estimated using the Kaplan-Meier method.

Results: A total of 161 patients diagnosed with gastric cancer underwent LAG. Postoperative morbidity occurred in 12 patients. The median OS was 67.0 months (range, 1.0 97.0 months), and the median DFS was 67.0 months (range, 1.0 97.0 months). T stage, N stage, TNM stage, lymphatic invasion, and venous invasion influenced overall survival and disease recurrence. The OS rates according to $\mathrm{N}$ stage were $96.8 \%$ for N0, $94.4 \%$ for N1, $45.5 \%$ for N2, and $42.9 \%$ for N3.

Conclusion: The current study showed that LAG for gastric cancer, including advanced gastric cancer, is technically feasible with acceptable long-term oncologic outcomes.

Keywords: Gastric cancer, Laparoscopy-assisted surgery, Overall survival

This is an Open Access article distributed under the terms of the Creative Commons Attribution Non-Commercial License (http:// creativecommons.org/licenses/by-nc/4.0/) which permits unrestricted non-commercial use, distribution, and reproduction in any medium, provided the original work is properly cited.
Received July 27, 2015

Revised 1st August 30, 2015

2nd September 6, 2015

3rd September 8, 2015

Accepted September 8, 2015

Corresponding author

Sung Ryol Lee

Department of Surgery,

Sungkyunkwan University School of Medicine, 108 Pyung-dong, Jongnogu, Seoul 03010, Korea

Tel: +82-2-2001-8005

Fax: +82-2-2001-2131

E-mail: dackang1@gmail.com
Copyright $\odot 2015$ The Journal of Minimally Invasive Surgery. All rights reserved.

\section{INTRODUCTION}

Although steady declines in the incidence and mortality rates of gastric cancer have been observed in the last century, gastric cancer is still one of the most common causes of cancer-related death in the world. ${ }^{1}$ The incidence of early gastric cancer (EGC) has increased in Korea in recent years because of the aging population, improved diagnostic procedures, and regular personal check-ups. ${ }^{2}$ The safety of laparoscopy-assisted gastrectomy (LAG) in early gastric cancer has been demonstrated in many studies. ${ }^{3,4}$ However, there has been significant debate over the use of laparoscopic resection for the management of advanced gastric cancer. Laparoscopic surgery has shown the advantages of less pain, shorter recovery time, shortened hospital stay, minimal wound and a good quality of life. ${ }^{7-9}$ For these reasons, LAG is considered an alternative treatment for gastric cancer. Although LAG is safe, the long-term oncologic efficacy and survival of patients including early and advanced gastric cancer have not been assessed. The aim of the present study was to discuss the long-term outcomes and survival of a group of patients who underwent LAG performed by a single surgeon. 


\section{MATERIALS AND METHODS}

\section{Patients}

Between January 2006 and December 2010, 171 patients who were diagnosed with gastric cancer underwent laparoscopic gastrectomy performed by a single surgeon in the Department of Surgery, Kangbuk Samsung Hospital, Sungkyunkwan University School of Medicine, Seoul, Korea. All cases were pathologically confirmed before surgery. In principle, all patients with gastric cancer were eligible for receiving a laparoscopic surgery. The patients pathologically diagnosed with advanced gastric cancer had to decide between laparoscopic surgery and open surgery. We explained this controversial point to the patients and have obtained their consent. Among a total of 171 patients who underwent laparoscopic gastrectomy, ten patients were converted to open gastrectomy due to abdominal adhesion $(\mathrm{n}=6)$ or uncontrolled bleeding in the operation field $(\mathrm{n}=4)$. Therefore, 161 patients were included in this study. Patients with advanced gastric cancer received chemotherapy with intravenous 5-fluorouracil and cisplatin; patients with EGC with lymph node metastasis received oral 5-fluorouracil for adjuvant treatment. Prior to the operation, the standard workup for evaluation and staging of gastric cancer was performed and included duodenoscopy and computed tomography (CT) scans.

\section{Surgical approach}

The patients were positioned supine on the operating room table under general anesthesia. An 18-gauge nasogastric tube was inserted to decompress the stomach. Two $12-\mathrm{mm}$ trocars, three $5-\mathrm{mm}$ trocars and a flexible laparoscope were used during surgery. Appropriate $\mathrm{CO}_{2}$ pneumoperitoneum was achieved with $15 \mathrm{mmHg}$ insufflations through a $12-\mathrm{mm}$ umbilical trocar. According to the Japanese Classification of Gastric Carcinoma, extended lymph node dissection (D2) and D1+b lymph node dissection were implemented. A mini laparotomy wound was created for extracorporeal operation. The incision was extended vertically $5 \mathrm{~cm}$ on the upper abdomen. The stomach was resected through the window. The Billroth I method was performed using a circular $29 \mathrm{~mm}$ stapler, but the Billroth II method was performed with hand sewing. In the case of total gastrectomy, the duodenum was transected 1 or $2 \mathrm{~cm}$ distal to the pyloric ring using a linear stapler. After the stomach was mobilized, the esophagus was transected using a purse string clamp through mini laparotomy wound. A side-to-side jejunojejunostomy was extracorporeally performed using linear staplers. Roux-en-Y esophagojejunostomy was accomplished using a circular stapler through mini laparotomy wound. A closed suction tube was placed in Morrison's pouch through the previous 5-mm trocar site.

\section{Outcome measurement}

All patients were monitored through physical examinations and laboratory tests after operation. Tumor markers, chest $\mathrm{X}$-ray, abdominal CT scan and duodenoscopy were examined every three months in the first two years, every sixth months in the following year and then annually thereafter. A positron emission tomography (PET) study was not always performed for patients. When the patient required additional analysis, PET or magnetic resonance imaging (MRI) was implemented to better clarify a recurrence. Demographics and perioperative and postoperative data were retrospectively collected and analyzed from the hospital records. Follow-up data were collected from patient's clinical records.

\section{Statistical analysis}

Overall survival (OS) and disease-free survival (DFS) were calculated using the Kaplan-Meier method. OS was calculated from the day of surgery until death or until the end of followup, and DFS was calculated until relapse or end of follow-up. The significant differences among each group of patients were determined by log rank test. $p$ values less than or equal to 0.05 were considered to be statistically significant. SPSS ver. 18.0 (SPSS, Inc., Chicago, IL, USA) was used for the statistical calculations. Multivariate analyses for survival and recurrence were estimated using Cox's proportional hazard model.

\section{RESULTS}

In total, 161 patients diagnosed with gastric cancer underwent LAG. After surgery, three patients were lost to follow-up. The patient characteristics and postoperative surgical results are summarized in Table 1. The study group consisted of 105 men and 56 women with a mean age of 62.6 years. Compared to women, men were twice as likely to develop gastric cancer. ${ }^{10}$ The average hospital stay after operation was 9.4 days. The five-year OS rate was $90.68 \%$, and the five-year DFS rate was $93.17 \%$.

According to the $7^{\text {th }}$ edition of the American Joint Committee on Cancer TNM classification system, there were 96 patients with stage IA cancer, 23 with stage IB cancer, 15 with stage IIA cancer, 12 with stage IIB cancer, 5 with stage IIIA cancer, 8 with stage IIIB cancer, 1 with stage IIIC and one with stage IV cancer, who died after 14 months due to disease progression. All operations were curative resection (R0) except one patient diagnosed with stage IV cancer. Postoperative 
Table 1. Clinicopathologic characteristics and postoperative surgical results of patients who underwent laparoscopy-assisted gastrectomy

\begin{tabular}{|c|c|}
\hline Clinicopathologic characteristics & Results \\
\hline Age (years, mean) & $62.64 \pm 11.37$ \\
\hline Sex (Male : Female) & $105: 56$ \\
\hline Gross type EGC, I : IIA : IIB : IIC : III & $10: 6: 40: 48: 12$ \\
\hline Gross type AGC, $1: 2: 3: 4$ & $2: 4: 39: 0$ \\
\hline Tumor size (cm, mean) & $3.33 \pm 1.95$ \\
\hline Histology (Undifferentiated : Differentiated) & $86: 75$ \\
\hline T stage (T1 : T2 : T3 : T4) & $114: 18: 19: 10$ \\
\hline N stage (N0 : N1 : N2 : N3) & $125: 18: 11: 7$ \\
\hline TNM stage $(I:$ : I : III : IV) & $119: 27: 14: 1$ \\
\hline Lymphatic invasion absence : presence & $122: 39$ \\
\hline Venous invasion absence : presence & $149: 12$ \\
\hline Perineural invasion absence : presence & $142: 19$ \\
\hline Proximal margin (cm, mean) & $4.78 \pm 3.19$ \\
\hline Distal margin (cm, mean) & $6.35 \pm 4.47$ \\
\hline Postoperative days (mean) & $9.37 \pm 5.27$ \\
\hline Type of operation (BI : BII : Total) & $95: 33: 33$ \\
\hline Extent of $\mathrm{LN}^{*}$ dissection $(\mathrm{D} 1+\mathrm{a}: \mathrm{D} 1+\mathrm{b}: \mathrm{D2})$ & $10: 84: 67$ \\
\hline Number of retrieved lymph nodes (mean) & $30 \pm 12.87$ \\
\hline \multicolumn{2}{|l|}{ Postoperative morbidity } \\
\hline Total & 12 \\
\hline Anastomosis site stenosis & 4 \\
\hline Anastomosis site bleeding & 1 \\
\hline Duodenal stump leakage & 2 \\
\hline Dysuria & 1 \\
\hline Wound infection & 2 \\
\hline Others & 2 \\
\hline Postoperative mortality & 1 \\
\hline
\end{tabular}

*Lymph node.

morbidity occurred in 12 patients. One patient died within 30 days due to duodenal stump leakage despite a second operation. The mean number of retrieved lymph nodes was 30 \pm 6 (range, 6 68, median 31.1) per patient.

In this study, the median OS was 67.0 months (range, 1.0 97.0 months) (Fig. 1), and the median DFS was 67.0 months (range, 1.0 97.0 months) (Fig. 2). The median followup period for all patients was 55.0 months (range, 1.0 97.0 months). Fifteen patients died (9.31\%) and 11 patients (6.83\%) had a recurrence of gastric cancer during the follow-up

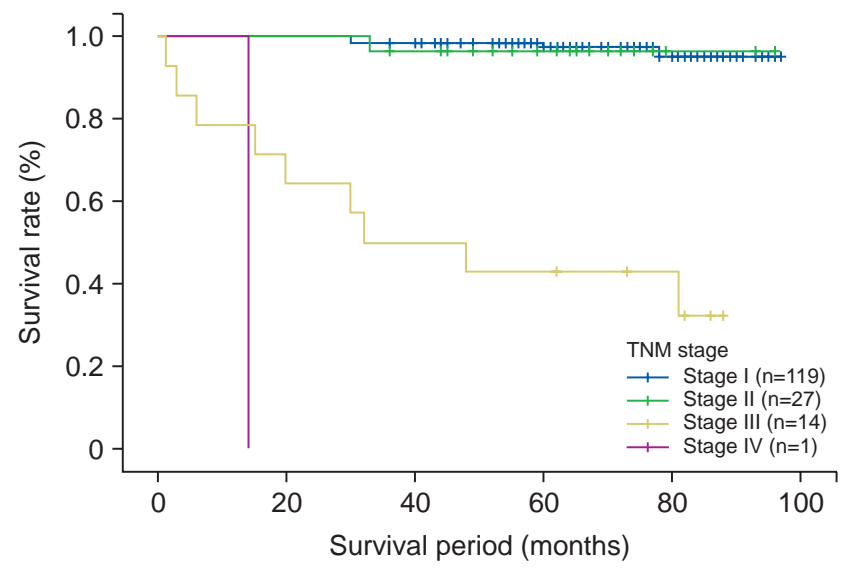

Fig. 1. Overall survival curves according to TNM stage.

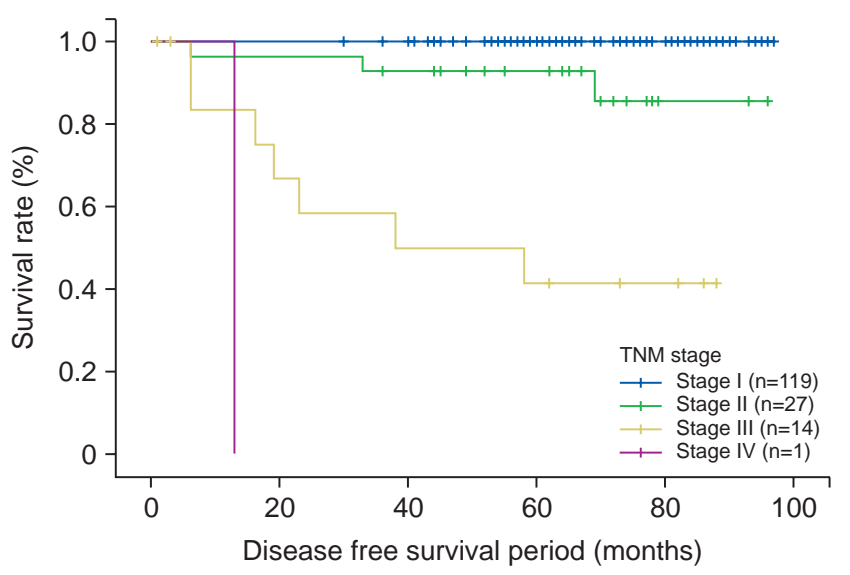

Fig. 2. Disease free survival curves according to TNM stage.

period. The causes of death were disease progression $(n=10)$, pneumonia $(n=1)$, gallbladder cancer $(n=1)$, and aging $(n=3)$.

Among the 11 recurred patients, 10 died. Most of the recurrences occurred within three years of the operation. The most common recurrent site was the peritoneum $(n=4)$, followed by lymph node $(n=3)$, liver $(n=2)$, anastomosis site $(n=1)$, and Krukenberg's tumor $(\mathrm{n}=1)$. The two patients diagnosed with EGC experienced liver and lymph node recurrence, respectively.

In this study, we evaluated the factors that influence OS and DFS. The different factors among the patients characteristic about five year survival rate are shown in Table 2. There were no significant differences in age, sex, or postoperative tumor differentiation among the patients groups. However, tumor size, T stage, N stage, TNM stage, lymphatic invasion, and venous invasion were significantly different. Based on univariate analysis, tumor size, T stage, $\mathrm{N}$ stage, lymphatic invasion, venous invasion and perineural invasion were significant prognostic factors for survival 
Table 2. Five-year survival rate of patients with laparoscopy-assisted gastrectomy

\begin{tabular}{|c|c|c|}
\hline Patients characteristic & Five year survival rate (\%) & $p$ value \\
\hline Age $\mid<60$ years $: \geq 60$ years $\mid$ & $95 \%: 89.3 \%$ & 0.105 \\
\hline Type of operation (BI : Bll : Total) & $93.68: 78.79: 100$ & 0.006 \\
\hline Extent of $L N$ dissection $(D 1+a: D 1+b: D 2)$ & $100: 95.24: 85.57$ & 0.152 \\
\hline Tumor size $(<$ mean : $\geq$ mean $)$ & $96.77: 85.29$ & 0.007 \\
\hline Histology (Differentiated : Undifferentiated) & $90.67: 94.08$ & 0.606 \\
\hline T stage (T1 : T2 : T3 : T4) & $97.37: 83.33: 89.47: 50$ & $<0.001$ \\
\hline N stage (N0 : N1 : N2 : N3) & $98.40: 94.44: 71.43: 42.86$ & $<0.001$ \\
\hline TNM stage $(\|:\|$ : III : IV) & $97.48: 96.30$ : $42.86:-$ & $<0.001$ \\
\hline Lymphatic invasion (absence : presence) & $97.54: 74.36$ & $<0.001$ \\
\hline Venous invasion (absence : presence) & $94.63: 58.33$ & $<0.001$ \\
\hline Perineural invasion (absence : presence) & $50.73 \%: 51.52$ & 0.283 \\
\hline
\end{tabular}

Table 3. Univariate and multivariate analyses of risk factors for five-year survival after laparoscopy-assisted gastrectomy

\begin{tabular}{|c|c|c|c|c|}
\hline \multirow{2}{*}{ Clinicopathological features } & \multicolumn{2}{|c|}{ Univariate analysis } & \multicolumn{2}{|c|}{ Multivariate analysis } \\
\hline & $\mathrm{HR}(95 \% \mathrm{CI})$ & $p$ value & $\mathrm{HR}(95 \% \mathrm{CI})$ & $p$ value \\
\hline Age $(<60$ years $: \geq 60$ years $)$ & $2.7(0.8 \sim 9.7)$ & 0.120 & & \\
\hline Sex (Male : Female) & $1.6(0.6 \sim 4.4)$ & 0.360 & & \\
\hline Tumor size $(<$ mean $: \geq$ mean $)$ & $4.29(1.4 \sim 13.6)$ & 0.010 & $0.9(.62 \sim 1.50)$ & 0.874 \\
\hline Histology (Undifferentiated : Differentiated) & $1.30(0.5 \sim 3.6)$ & 0.610 & $0.3(.049 \sim 1.43)$ & 0.123 \\
\hline \multicolumn{5}{|l|}{ T stage } \\
\hline $\mathrm{T} 2 / \mathrm{T} 1$ & $4.71(1.051 \sim 21.069)$ & 0.040 & $3.5(.41 \sim 29.89)$ & 0.253 \\
\hline T3/T1 & $3.25(0.595 \sim 17.779)$ & 0.140 & $1.2(.08 \sim 16.42)$ & 0.910 \\
\hline T4/T1 & $20.28(5.712 \sim 72.011)$ & $<0.001$ & $5.1(.41 \sim 64.15)$ & 0.206 \\
\hline \multicolumn{5}{|l|}{ N stage } \\
\hline N1/NO & $2.02(0.225 \sim 18.170)$ & 0.530 & $0.83(.06 \sim 11.37)$ & 0.888 \\
\hline N2/NO & $20.84(5.854 \sim 74.160)$ & $<0.001$ & $26.4(2.26 \sim 308.99)$ & 0.009 \\
\hline N3/NO & 26.91 (6.702 108.015) & $<0.001$ & $9.9(0.58 \sim 171.32)$ & 0.113 \\
\hline Lymphatic invasion (Yes/No) & 10.09 (3.209 31.698) & $<0.001$ & $2.13(0.26 \sim 17.44)$ & 0.480 \\
\hline Venous invasion (Yes/No) & $9.08(3.204 \sim 25.746)$ & $<0.001$ & $1.79(0.19 \sim 17.21)$ & 0.613 \\
\hline Perineural invasion (Yes/No) & $5.27(1.87 \sim 14.85)$. & 0.002 & $0.48(0.05 \sim 4.33)$ & 0.625 \\
\hline
\end{tabular}

(Table 3). A multivariate analysis was performed to identify independent prognostic factors using the Cox's proportional hazards model with the forward method. The factors related to the academic significance or the prognosis with univariate analysis included $\mathrm{T}$ stage, $\mathrm{N}$ stage, lymphatic invasion, venous invasion, perineural invasion, and tumor histology. Based on multivariate analysis, N2 stage was the most important prognostic factor (Table 3). In this study, the OS rates according to $\mathrm{N}$ stage were $96.8 \%$ for N0, $94.4 \%$ for N1, $45.5 \%$ for $\mathrm{N} 2$, and $42.9 \%$ for N3 ( $p<0.001$ ) (Fig. 3). The factors that influenced disease recurrence included most of these same factors (Table 4). However, the most powerful factor for disease recurrence was the presence of lymphatic invasion (Table 5). 


\section{DISCUSSION}

Since Kitano et al. ${ }^{11}$ first applied and described laparoscopic gastrectomy in 1994, there has been significant debate over the use of laparoscopic surgery in gastric cancer. Laparoscopic approaches in early gastric cancer have been shown to improve recovery time, lessen pain, result in faster return of gastrointestinal function, show cosmetic benefit, and result in better pulmonary function. ${ }^{7-9,12}$ Several studies have also demonstrated the efficacy of laparoscopic surgery and oncologic safety in EGC. ${ }^{8,12,13}$ However, there is still debate about LAG in advanced gastric cancer. ${ }^{3,4}$ The major concerns with the laparoscopic approach are the completeness of oncologic resection and D2 lymphadenectomy in advanced

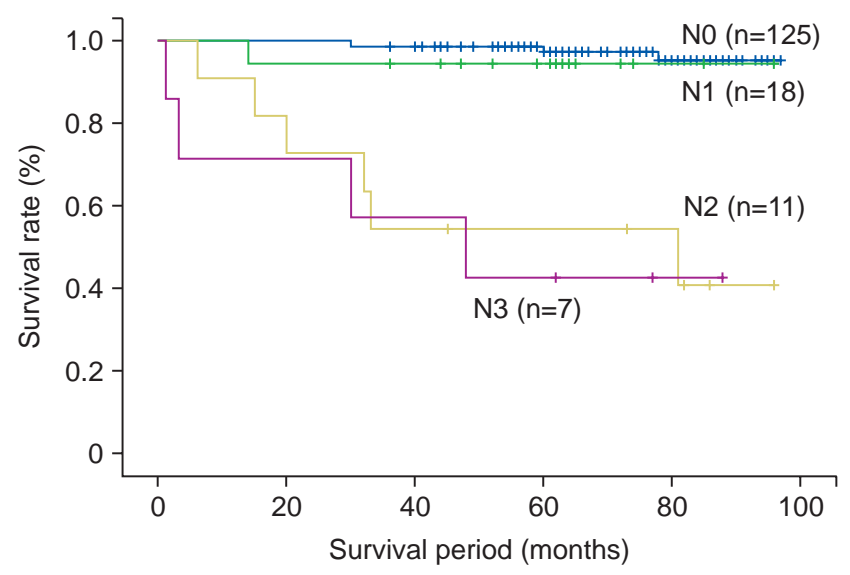

Fig. 3. Overall survival curves according to $\mathrm{N}$ stage. gastric cancer. The aim of study was to evaluate long-term outcomes and survival of patients with LAG including advanced gastric cancer.

The presence of lymph node metastases in EGC worsens prognosis, as reported by Kitamura et al. ${ }^{14}$ and Maehara et al. ${ }^{15}$ Also, several studies have shown that adequate lymph node dissection is the most important procedure. ${ }^{16,17}$ The majority of patients in this study were treated using laparoscopic D2 lymph node dissection except for high-risk patients with cardiopulmonary disease and old age ( $>75$ years). Instead, D1+b lymph node dissection conducted for high-risk patients. The mean number of retrieved LNs was $30 \pm 6$ (range, 6 68, median 31.1) per patient, comparable to the 20 40 retrieved LNs reported by previous studies on the use of open conventional gastrectomy and laparoscopic gastrectomy. ${ }^{17-20}$

According to a multicenter, prospective, randomized clinical study of the Korean Laparoscopic Gastrointestinal Surgical Society that included 179 LAG patients, LAG for gastric cancer has an $11.6 \%$ early morbidity and $1 \%$ mortality rate. ${ }^{21}$ Lin et al. ${ }^{18}$ reported a morbidity rate of $13.6 \%$ and mortality rate of $0.3 \%$. In the present study, the mortality and morbidity rates were $0.62 \%$ and $9.31 \%$, respectively. Compared to the results of previous studies, ${ }^{17-21}$ the surgical outcome of LAG for gastric cancer including advanced gastric cancer in the present study was technically comparable.

Pak et al. ${ }^{22}$ analyzed 714 patients who underwent LAG for gastric cancer and reported five-year OS rates of $96.4 \%$ in stage I, $83.1 \%$ in stage II, and $50.2 \%$ in stage III and fiveyear DFS rates of $95.8 \%$ in stage I, $83.4 \%$ in stage II, and $46.4 \%$ in stage III. Kitano et al. $^{23}$ also reported on the long-

Table 4. Disease-free survival rates of patients who underwent laparoscopy-assisted gastrectomy

\begin{tabular}{|c|c|c|}
\hline Patient characteristic & Disease-free survival rate (\%) & $p$ value \\
\hline Age $(<60$ years $: \geq 60$ years $)$ & $93.75: 92.78$ & 0.811 \\
\hline Se (Male : Female) & $96.19: 94.23$ & 0.037 \\
\hline Type of operation (BI : Bll : Totall) & $92.63: 90.90: 96.97$ & 0.562 \\
\hline Extent of $\mathrm{LN}^{*}$ dissection (D1 + $\mathrm{a}: \mathrm{D} 1+\mathrm{b}: \mathrm{D2}$ ) & $100: 96.43: 88.06$ & 0.103 \\
\hline Tumor size $(<$ mean $: \geq$ mean $)$ & $98.92: 85.29$ & 0.001 \\
\hline Histology (Undifferentiated : differentiated) & $90.70: 96.00$ & 0.183 \\
\hline T stage (T1 : T2 : T3 : T4) & $99.12: 94.44: 78.95: 50.00$ & $<0.001$ \\
\hline N stage (N0 : N1 : N2 : N3) & $99.20: 88.89: 45.45: 71.43$ & $<0.001$ \\
\hline TNM stage $(\mid$ : II : III : IV) & $100: 88.89: 42.45:-$ & $<0.001$ \\
\hline Lymphatic invasion (absence : presence) & $99.18: 74.36$ & $<0.001$ \\
\hline Venous invasion (absence : presence) & $95.97: 58.33$ & $<0.001$ \\
\hline Perineural invasion (absence : presence) & $92.00: 63.16$ & 0.267 \\
\hline
\end{tabular}

*Lymph node. 
Table 5. Univariate and multivariate analyses of risk factors for disease-free survival after laparoscopy-assisted gastrectomy

\begin{tabular}{|c|c|c|c|c|}
\hline \multirow{2}{*}{ Clinicopathological features } & \multicolumn{2}{|c|}{ Univariate analysis } & \multicolumn{2}{|c|}{ Multivariate analysis } \\
\hline & $\mathrm{HR}(95 \% \mathrm{Cl})$ & $p$ value & $\mathrm{HR}(95 \% \mathrm{CI})$ & $p$ value \\
\hline Age $(<60$ years $: \geq 60$ years $)$ & $1.16(0.34 \sim 3.97)$ & 0.812 & & \\
\hline Sex (Male : Female) & $3.40(0.99 \sim 11.62)$ & 0.051 & & \\
\hline Tumor size $(<$ mean : $\geq$ mean) & $15.19(1.94 \sim 118.82)$ & 0.010 & $0.99(0.91 \sim 1.08)$ & 0.814 \\
\hline Histology (Undifferentiated : Differentiated) & $2.39(0.634 \sim 9.03)$ & 0.197 & $1.22(0.85 \sim 1.74)$ & 0.278 \\
\hline \multicolumn{5}{|l|}{ T stage } \\
\hline $\mathrm{T} 2 / \mathrm{T} 1$ & $6.70(0.42 \sim 107.12)$ & 0.179 & $0.67(0.20 \sim 2.20)$ & 0.505 \\
\hline T3/T1 & $26.27(2.934 \sim 235.19)$ & 0.003 & $0.71(0.20 \sim 2.51)$ & 0.594 \\
\hline T4/T1 & 74.161 (8.65 636.11) & $<0.001$ & $0.73(0.25 \sim 2.13)$ & 0.563 \\
\hline \multicolumn{5}{|l|}{$\mathrm{N}$ stage } \\
\hline N1/NO & $16.24(1.47 \sim 179.78)$ & 0.023 & $0.95(0.29 \sim 3.11)$ & 0.938 \\
\hline N2/NO & $88.95(10.67 \sim 741.10)$ & $<0.001$ & $1.19(0.34 \sim 4.24)$ & 0.786 \\
\hline N3/ NO & 5712 (5.17 630.59) & 0.001 & $1.04(0.33 \sim 3.29)$ & 0.952 \\
\hline Lymphatic invasion (Yes/No) & $38.05(4.87 \sim 297.52)$ & 0.001 & $1.72(1.05 \sim 2.82)$ & 0.03 \\
\hline Venous invasion (Yes/No) & $12.56(3.83 \sim 41.25)$ & $<0.001$ & $0.87(0.37 \sim 2.02)$ & 0.745 \\
\hline Perineural invasion (Yes/No) & $15.07(4.40 \sim 51.62)$ & $<0.001$ & $0.51(0.21 \sim 1.27)$ & 0.148 \\
\hline
\end{tabular}

term outcome of laparoscopic gastrectomy in a retrospective multicenter study on LAG for early gastric cancer, noting fiveyear DFS rates of 99.8, 98.7, and $85.7 \%$ for stages IA, IB, and II, respectively. This present study showed OS of stage I, II, and III of 96.63, 96.30, and 35.71\%, respectively, and DFS of 100\% for stage I, $88.89 \%$ for stage II and $50 \%$ for stage III. Compared with multicenter studies, ${ }^{21-24}$ the present OS and the DFS were comparable. The oncologic outcome is similar to that of conventional open surgeries and previous laparoscopic surgeries. Therefore, these results indicate that laparoscopic gastrectomy has acceptable long-term oncologic outcomes for LAG in gastric cancer.

Based on Table 3 results, only N2 stage was a significant prognostic factor for the five-year OS. The data accumulated $\mathrm{n}$ the hospital show that the number of patients with greater than stage III disease was too small, and that most patients were in a relatively early stage. For this reason, it is assumed that N1 stage and N3 stage were not a significant factor for the five-year OS. Therefore, it is yet to be discussed to regard N stage as a prognostic factor for five-year OS.

Table 4 shows the factors that influenced disease recurrence. The recurrence site varied, with peritoneum $(n=4)$ being the most common recurrent site, and lymph node as the second most recurrent organ $(n=3)$. These recurrent patterns are similar to those of a previous open gastrectomy study. ${ }^{25}$ Table 5 shows the prognostic factors for recurrence of gastric cancer.
Previous studies ${ }^{14,15}$ have shown that the presence of lymph node metastases in gastric cancer worsens prognosis. In the present study, lymphatic invasion was the most powerful prognostic factor of disease recurrence.

There were some limitations associated with this present study. There was no open control group against which to evaluate the safety of laparoscopic surgery compared to open gastrectomy. The data were retrospectively collected and reviewed. To overcome these limitations, a multicenter, prospective and randomized controlled study is necessary.

In conclusion, the present study shows that LAG for gastric cancer including advanced gastric cancer is technically feasible and has acceptable long-term oncologic outcomes.

\section{REFERENCES}

1) Roder DM. The epidemiology of gastric cancer. Gastric Cancer 2002;5 Suppl 1:5-11.

2) Lee SR, Kim HO, Son BH. Long-term outcomes and survival of patients undergoing laparoscopy-assisted distal gastrectomy for gastric cancer. J Laparoendosc Adv Surg Tech A 2012;22:432-437.

3) Mochiki E, Nakabayashi T, Kamimura H, Haga N, Asao T, Kuwano H. Gastrointestinal recovery and outcome after laparoscopy-assisted versus conventional open distal gastrectomy for early gastric cancer. World J Surg 2002;26:1145-1149.

4) Chen K, Xu XW, Mou YP, et al. Systematic review and meta- 
analysis of laparoscopic and open gastrectomy for advanced gastric cancer. World J Surg Oncol 2013;11:182.

5) Hur H, Jeon HM, Kim W. Laparoscopy-assisted distal gastrectomy with D2 lymphadenectomy for T2b advanced gastric cancers: three years' experience. J Surg Oncol 2008;98:515-519.

6) Kawamura H, Homma S, Yokota R, et al. Inspection of safety and accuracy of D2 lymph node dissection in laparoscopy-assisted distal gastrectomy. World J Surg 2008;32:2366-2370.

7) Han HS, Kim YW, Yi NJ, Fleischer GD. Laparoscopy-assisted D2 subtotal gastrectomy in early gastric cancer. Surg Laparosc Endosc Percutan Tech 2003;13:361-365.

8) Lee JH, Han HS, Lee JH. A prospective randomized study comparing open vs laparoscopy-assisted distal gastrectomy in early gastric cancer: early results. Surg Endosc 2005;19:168-173.

9) Asao T, Hosouchi Y, Nakabayashi T, Haga N, Mochiki E, Kuwano H. Laparoscopically assisted total or distal gastrectomy with lymph node dissection for early gastric cancer. Br J Surg 2001;88:128132.

10) Parkin DM, Bray FI, Devesa SS. Cancer burden in the year 2000. The global picture. Eur J Cancer 2001;37 Suppl 8:S4-66.

11) Kitano S, Iso Y, Moriyama M, Sugimachi K. Laparoscopy-assisted Billroth I gastrectomy. Surg Laparosc Endosc 1994;4:146-148.

12) Kitano S, Shiraishi N, Fujii K, Yasuda K, Inomata M, Adachi Y. A randomized controlled trial comparing open vs laparoscopyassisted distal gastrectomy for the treatment of early gastric cancer: an interim report. Surgery 2002;131:S306-311.

13) Lee JH, Yom CK, Han HS. Comparison of long-term outcomes of laparoscopy-assisted and open distal gastrectomy for early gastric cancer. Surg Endosc 2009;23:1759-1763.

14) Kitamura K, Yamaguchi T, Taniguchi H, Hagiwara A, Sawai K, Takahashi T. Analysis of lymph node metastasis in early gastric cancer: rationale of limited surgery. J Surg Oncol 1997;64:42-47.

15) Maehara $Y$, Orita H, Okuyama $T$, et al. Predictors of lymph node metastasis in early gastric cancer. Br J Surg 1992;79:245-247.
16) Zheng $\mathrm{Z}$, Liu $\mathrm{Y}, \mathrm{Bu} \mathrm{Z}$, et al. Prognostic role of lymph node metastasis in early gastric cancer. Chin J Cancer Res 2014;26:192199.

17) Tanimura S, Higashino M, Fukunaga $Y$, et al. Laparoscopic distal gastrectomy with regional lymph node dissection for gastric cancer. Surg Endosc 2005;19:1177-1181.

18) Lin JX, Huang CM, Zheng CH, et al. Surgical outcomes of 2041 consecutive laparoscopic gastrectomy procedures for gastric cancer: a large-scale case control study. PLoS One 2015;10:e0114948.

19) Mochiki E, Kamiyama Y, Aihara R, Nakabayashi T, Asao T, Kuwano H. Laparoscopic assisted distal gastrectomy for early gastric cancer: Five years' experience. Surgery 2005;137:317-322.

20) Noshiro H, Nagai E, Shimizu S, Uchiyama A, Tanaka M. Laparoscopically assisted distal gastrectomy with standard radical lymph node dissection for gastric cancer. Surg Endosc 2005;19: 1592-1596.

21) Kim HH, Hyung WJ, Cho GS, et al. Morbidity and mortality of laparoscopic gastrectomy versus open gastrectomy for gastric cancer: an interim report--a phase III multicenter, prospective, randomized Trial (KLASS Trial). Ann Surg 2010;251:417-420.

22) Pak KH, Hyung WJ, Son T, et al. Long-term oncologic outcomes of 714 consecutive laparoscopic gastrectomies for gastric cancer: results from the 7-year experience of a single institute. Surg Endosc 2012;26:130-136.

23) Kitano S, Shiraishi N, Uyama I, Sugihara K, Tanigawa N. A multicenter study on oncologic outcome of laparoscopic gastrectomy for early cancer in Japan. Ann Surg 2007;245:68-72.

24) Yoo HM, Lee HH, Shim JH, et al. Long-term outcomes and survival after laparoscopy-assisted distal gastrectomy for gastric cancer: three-year survival analysis of a single-center experience in Korea. J Surg Oncol 2011;104:511-515.

25) Yoo CH, Noh SH, Shin DW, Choi SH, Min JS. Recurrence following curative resection for gastric carcinoma. Br J Surg 2000; 87:236-242. 